\title{
MultileVel MeSh Free Method FOR THE TORSION PROBLEM
}

\author{
Kozulic, V.; Gotovac, B. \& COLAK, I.
}

Abstract: This paper presents a mesh free method for solving the torsion problem of prismatic bars. This method applies Fup basis functions, which belong to the class of Rvachev's infinitely derivable finite functions. As it is possible to calculate derivation values of Fup basis functions of high degree in a precise yet simple way, so it is possible efficiently to apply strong formulation procedures. The proposed method represents the problem domain and its boundaries by a set of nodes rather than resorting to the traditional discretization into finite elements. The collocation method was used to form a system of equations in which the differential equation of the problem is satisfied in collocation points of closed domain, while boundary conditions are satisfied exactly at the domain boundary. The proposed mesh free method offers a multilevel approach that achieves the approximate solution of an arbitrary accuracy by hierarchically increasing the number of basis functions in the domain. Values of the main solution function and all the values derived from the main solution are calculated in same points since numerical integration is avoided. The presented numerical model is illustrated by examples of linear and elasto-plastic analyses of prismatic bars subjected to torsion. The propagation of plastic zones in the cross-section is monitored by applying the incremental iterative procedure until its failure.

Key words: mesh free method, basis functions, universality, collocation method, multilevel numerical model, plastic failure
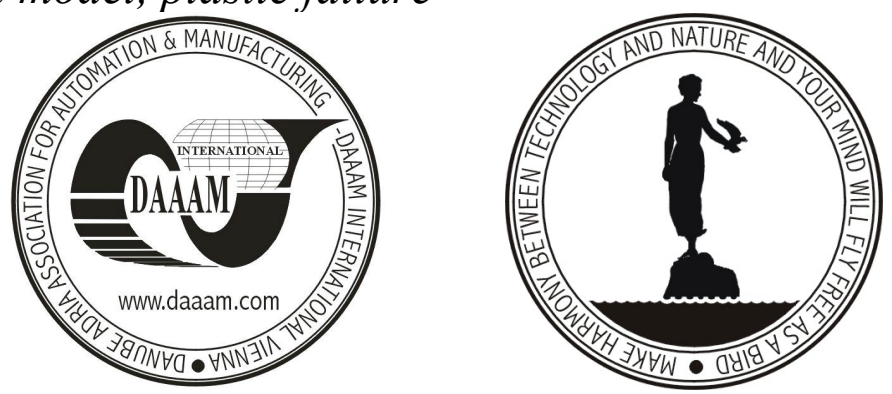

Authors' data: Associate Professor Kozulic V.[edrana]*, Professor Gotovac B.[laz]*, Associate Professor Colak I.[vo]**, *Faculty of Civil Engineering and Architecture, University of Split, Croatia, ** Faculty of Civil Engineering, University of Mostar, Bosnia and Herzegovina, Vedrana.Kozulic@gradst.hr, Blaz.Gotovac@gradst.hr, gf-svemo@tel.net.ba

This Publication has to be referred as: Kozulic, V.; Gotovac, B. \& Colak, I. (2006). Multilevel Mesh Free Method for the Torsion Problem, Chapter 29 in DAAAM International Scientific Book 2006, B. Katalinic (Ed.), Published by DAAAM International, ISBN 3-901509-47-X, ISSN 1726-9687, Vienna, Austria DOI: $10.2507 /$ daaam.scibook.2006.29 